\title{
Peculiarities of sorption isotherm and sorption chemisms of caesium by mixed nickel-potassium ferrocyanide based on hydrated titanium dioxide
}

\author{
A. V. Voronina $\cdot$ V. S. Semenishchev $\cdot$ \\ E. V. Nogovitsyna $\cdot$ N. D. Betenekov
}

Received: 9 October 2012/Published online: 12 April 2013

(C) Akadémiai Kiadó, Budapest, Hungary 2013

\begin{abstract}
Sorption isotherm of caesium from tap water by mixed nickel-potassium ferrocyanide based on hydrated titanium dioxide is obtained for a wide range of concentrations of caesium. It is shown that there are three types of specificity to caesium sorption sites in this sorbent. Sorption chemisms of caesium are studied, factors conditioned high sorption capacity of the sorbent are revealed. It is shown that occupation of sorption sites I and II is well approximated by Langmuir equilibrium and this process can be described within the bounds of theory of ion exchange. The expected sorption chemism of caesium by sorption sites III at high concentrations of caesium $\left(>50 \mathrm{mg} \mathrm{L}^{-1}\right)$ is precipitation of mixed nickel-caesium ferrocyanide in pore space of the sorbent.
\end{abstract}

Keywords Sorption - Radionuclide - Ferrocyanide · Isotherm $\cdot$ Ion exchange $\cdot$ Kinetics

\section{Introduction}

Mixed ferrocyanides of transition metals are the most specificity sorbents for sorption of caesium radionuclides from aqueous media with various salinity. Various methods can be used for synthesis of ferrocyanides: precipitation of sediments with further granulation by freezing or drying [1, 2], precipitation of ferrocyanides onto surfaces of inert supports (glass, silica gel, alumogel, cellulose, polyethylene

A. V. Voronina · V. S. Semenishchev $(\bowtie)$

E. V. Nogovitsyna · N. D. Betenekov

Ural Federal University, Ekaterinburg, Russia

e-mail:vovius82@mail.ru

A. V. Voronina

e-mail: av.voronina@mail.ru terephthalate, polypropylene membranes) $[3,4]$, modification of sorption active supports (ion exchange resins, aluminosilicates, hydrated oxides) by ferrocyanides [5-9], synthesis of composition sorbents including ferrocyanides of transition metals and silica gel [10,11], sol-gel method [12]. The detail review of methods of synthesis of sorbents (including ferrocyanides) can be found in the work [13].

Various ferrocyanide sorbents, obtained via various methods, have their virtues, shortcomings and scopes. For example, granulated materials possess poor mechanical strength, low availability of sorption sites and slow sorption kinetics. Synthesis of ferrocyanides on supports allowing to improve mechanical properties as well as promotes full realization of ion exchange capacity and increasing of sorption kinetics. However, the capacity of thin-layer sorbents is usually quite low, therefore the most prospective scope of them is radiochemical analysis. Distribution coefficients of caesium for various types of ferrocyanide sorbents are up to $10^{3}-10^{6} \mathrm{~mL} \mathrm{~g}^{-1}$.

Ferrocyanide sorbents can possess various types of sorption sites, therefore some difficulties, connected with complexity of profiles of sorption isotherms and explaining of obtained sorption features, may appear.

The exchange of caesium ions on ferrocyanides with obtaining of Langmuir isotherms is considered as the main sorption chemism in works [9-11], but there is no any information about reversibility of sorption. In the work [14] sorption on ferrocyanides is described by Freundlich isotherm. In the work [15] sorption sites of ferrocyanides, obtained via co-precipitation and further granulation, are characterized, and probable sorption chemisms of ions from solutions are described: exchange of metal or $\mathrm{H}_{3} \mathrm{O}^{+}$ ions located in structural interstice for metal ions from solution; incorporation of ions from solution into structural interstice, where uncompensated electrostatic charge or 
coordination unsaturation present on neighbouring atoms; exchange of metal(s) ions of matrix of a sorbent for metal(s) ions from solution; exchange of protons of hydroxyl groups in extreme locations for ions with high coordinating affinity.

The possibility of uptake of cations by transition metals ferrocyanides is conditioned by their channel structure [16, 17]. Structure of sparingly soluble ferrocyanides is similar to the structure of finely porous D-class zeolites with channels diameters at 3.0-3.5 $\AA$; alkaline ions with similar sizes (ion diameter of $\mathrm{Rb}^{+}=2.96 \AA$, ion diameter of $\mathrm{Cs}^{+}=3.38 \AA$ ) can be fixed in such channels [18]. Alkaline ions and part of transition metal ions locating in interstices of crystal lattice neutralize residual charge of ferrocyanide carcass and can exchange for another cations from solution [16, 19, 20]. Alkaline and other cations are fixed in interstices of negatively charged ferrocyanide crystal lattice due to forces of electrostatic and dispersive interaction and this retention increases with increasing of ion sizes $[16,19]$. The cause of such retention is increasing of polarization interaction of exchanging ions with $\mathrm{CN}$ groups of ferrocyanides.

Many works [20-23] are dedicated to study of sorption features and structure of ferrocyanides. It is shown, that more complex types of sorption chemisms, than ion exchange, are typical for ferrocyanides. Common description of the following main sorption processes possible for ferrocyanides can be found in [23]: ion exchange (equivalent exchange of ions), molecular adsorption (uptaking of equivalent quantities of anions and cations of salts by a sorbent), electron exchange (uptaking or escape of ions by a sorbent connected with reduction or oxidation of ions entering into the composition of sorbent's matrix), heterogenous ion-exchange reaction (equivalent exchange of ions, formation and development of a new phase, coexistence of two phases during the reaction; such processes are usually irreversible, degree of transformation strongly depends on temperature, sorption isotherms have the peculiar appearance). In the work [2] the influence of temperature on sorption of caesium is described and supposition about the presence of irreversible heterogenous ion-exchange reaction on ferrocyanides is made.

The work [24] is of great interest; there is shown that the most dominate process of interphase redistribution for ferrocyanides with relatively homogeneous sorption sites is compensated adsorption of cation-anion pairs (molecular sorption). Also the role of molecular sorption of alkaline ions is quantitatively analysed in this work.

In the work [8] authors proposed the method of surface modification of hydrated titanium dioxide by mixed ferrocyanides, that allowing obtain sorbents with high specificity and selectivity to caesium as well as with high capacity, radiation stability and low leaching rates of radionuclides [25, 26]. Such sorbents can also be used as matrices for joint immobilization of long-lived $\beta$-emitting caesium and strontium radionuclides from liquid radioactive wastes with the aim of further disposal. The high selectivity and capacity with respect to caesium and irreversibility of sorption are connected with peculiarities ferrocyanide phase, formed on the surface of hydrated titanium dioxide [8], as well as with sorption chemisms of caesium. This article describes expected sorption chemisms of caesium by mixed nickel-potassium ferrocyanide based on hydrated titanium dioxide and revelation of factors conditioned high sorption capacity of the sorbent.

\section{Experimental}

Studies of caesium sorption were performed under static conditions from tap water spiked by ${ }^{137} \mathrm{Cs}$. The content of hardness salts, alkali metals, and anions in tap water corresponded to SanPiN (sanitary rules and regulations) 2.1.4.1074-01. Namely, the total hardness was $2.4 \mathrm{mg}$ equiv $\mathrm{L}^{-1}$, concentration of $\mathrm{Ca}, \mathrm{K}, \mathrm{Na}$ and $\mathrm{Fe}$ were $30 \pm 5,2.7 \pm 0.9,20 \pm 5$ and $0.2 \pm 0.1 \mathrm{mg} \mathrm{L}^{-1}$ respectively. Water was preliminarily settled and filtered to remove iron hydroxide. The following parameters were used: solution volume $V=50 \mathrm{~mL}$, sorbent weight $m=20 \mathrm{mg}, \mathrm{pH}=7.8 \pm 0.2$, time $t=1$ week. Initial concentrations of caesium in solutions (in the range of $10^{-7}-10^{3} \mathrm{mg} \mathrm{L}^{-1}$ ) were specified using standard solutions of $\mathrm{CsCl}$. Determinations of caesium concentration were performed via radioactive-tracer technique using ${ }^{137} \mathrm{Cs}$. Samples were measured via beta-radiometry using betaradiometer "UI-38P" (USSR). The isotherm of caesium sorption is presented as curve in coordinates " $\mathrm{gg} \mathrm{C}_{\text {solid }}-\mathrm{lg}$ $\mathrm{C}_{\text {liquid", }}$, where $\lg \mathrm{C}_{\text {solid }}$ is logarithm of concentration of caesium in solid phase $\left(\mathrm{g} \mathrm{g}^{-1}\right)$ and $\lg \mathrm{C}_{\text {liquid }}$ is logarithm of concentration of caesium in liquid phase $\left(\mathrm{g} \mathrm{L}^{-1}\right)$.

Samples of mixed nickel-potassium ferrocyanide saturated by caesium were obtained and researched using physical-chemical methods of analysis for revelation of sorption chemisms. Saturation of sorbent samples by caesium was performed from $\mathrm{CsCl}$ solution with caesium concentration at $100 \mathrm{mg} \mathrm{L}^{-1}$.

Infrared spectra (IR-spectra) of initial sorbent samples and samples saturated by caesium under static conditions were obtained. Measurements were performed in $\mathrm{KBr}$ disk on IR-Raman-spectrometer 'Vertex-70' with add-on device RAM-II (Bruker, Germany). Interpretation of IR-spectra was performed via comparison with on-line database [27]. Texture of surfaces of samples was analysed using scanning electron microscope (SEM) 'LEO-420' (Carl Zeiss, Germany). Specific surface areas of samples were determined via adsorption-desorption of nitrogen on high-speed 
analyser of surface areas and pore sizes 'Nova 1200e' (Quantachrome, USA).

Sorption kinetics of caesium by mixed nickel-potassium ferrocyanide based on hydrated titanium dioxide were studied under the following parameters: tap water with concentration of caesium at $100 \mathrm{mg} \mathrm{L}^{-1}, \mathrm{pH} 7.8 \pm 0.2$, $T=293 \mathrm{~K}$, ratio of volume of solution and sorbent weight $\mathrm{V} / \mathrm{m}=100 \mathrm{~mL} / 50 \mathrm{mg}$, stirring rate at $490 \mathrm{rpm}$. Determinations of caesium concentration were performed via radioactive-tracer technique using ${ }^{137} \mathrm{Cs}$ as in static studies.

For explanation of chemisms of caesium sorption under high concentrations of caesium $\left(>50 \mathrm{mg} \mathrm{L}^{-1}\right)$ sorption kinetics was also studied for hydrated titanium dioxide. This material was used as a support for synthesis of studied mixed nickel-potassium ferrocyanide sorbent. Hydrated titanium dioxide was previously saturated by nickel (to its concentration in sorbent at $10.7 \mathrm{mg} \mathrm{g}^{-1}$ ) and then was treated by $\mathrm{K}_{4}\left[\mathrm{Fe}(\mathrm{CN})_{6}\right]$ solution (in accordance with method of synthesis as described in [8]).

Under realized conditions of synthesis of mixed nickelpotassium ferrocyanide based on hydrated titanium dioxide, the $\mathrm{K}_{4}\left[\mathrm{Fe}(\mathrm{CN})_{6}\right]$ solution may present in developed pore space of the sorbent and migrate into reaction solution during sorption of caesium. In addition, the transfer of ferrocyanide ions into reaction solution is possible at the expense of desorption of molecular-adsorbed potassium ferrocyanide $\mathrm{K}_{4}\left[\mathrm{Fe}(\mathrm{CN})_{6}\right]$, as well as due to partial dissolving of mixed nickel-potassium ferrocyanide phase. Therefore, in kinetics studies of caesium sorption experiences with introduction of $\mathrm{K}_{4}\left[\mathrm{Fe}(\mathrm{CN})_{6}\right]$ into the solution were performed. Potassium ferrocyanide was added to solution in the beginning of the experience, the solution was well mixed for achieving of homogeneous distribution, its concentrations in the solution were 49 and $106 \mathrm{mg} \mathrm{L}^{-1}$. These concentrations of $\mathrm{K}_{4}\left[\mathrm{Fe}(\mathrm{CN})_{6}\right]$ corresponded to concentrations calculated under two boundary conditions: minimal concentration at $49 \mathrm{mg} \mathrm{L}^{-1}$ transfering into solution during sorption from the pores of the sorbent (volume of pores is $0.40 \mathrm{~cm}^{3} \mathrm{~g}^{-1}$ ), and maximal concentration corresponding to complete dissolving of mixed nickel-potassium ferrocyanide phase $\left(106 \mathrm{mg} \mathrm{L}^{-1}\right)$.

The results of kinetics studies are presented as curves in coordinates $«-\ln (1-F)-t »$, where $F=S_{\tau} / S_{\infty}$ is the degree of achieving of sorption equilibrium, $t$ is the time (min), $S_{\tau}$ is the degree of sorption of caesium at time $t, S_{\infty}$ is the equilibrium degree of sorption of caesium (after 1 week). $S$ is the degree of sorption of caesium calculated in accordance with (1):

$S=\frac{I_{\text {in }}-I_{\text {end }}}{I_{\text {in }}-I_{\mathrm{b}}}$

$I_{\text {in }}, I_{\text {end }}$ is the initial and final count rate of the solution, cp, $I_{b}$ is the background count rate, cpm.

\section{Results and discussion}

Preliminary experiences have shown that sorption of caesium by glass vessels is negligibly small under these conditions. Competitive sorption of monovalent ions $\mathrm{Na}^{+}$and $\mathrm{K}^{+}$) by the mixed nickel-potassium ferrocyanide based on hydrated titanium dioxide from tap water is absent [28], sorption of $\mathrm{Ca}$ is not competitive for $\mathrm{Cs}$ and is realized at the expense of hydrated titanium dioxide phase [29].

The experimental curve of sorption isotherm of caesium by the mixed nickel-potassium ferrocyanide based on hydrated titanium dioxide from tap water is shown at Fig. 1 (curve 1). Three linear parts can be found on the sorption isotherm, this indicates that the sorbent has three various types of specificity to caesium sorption sites with various values of distribution coefficients $\left(K_{\mathrm{d}}\right)$ and static exchange capacity (SEC). Slopes of linear parts of the isotherm, equilibrium $K_{\mathrm{d}}$, static exchange capacities of various sorption sites and parameters of sorption affinity were calculated using the technique of least squares. The results of statistical data treatment of the isotherm are presented at the Table 1.

The obtained data show that there is direct proportional dependence between concentrations of caesium in solution and solid phase in certain regions of concentrations of the sorbate: slopes of linear parts of the isotherm for regions of concentrations at $\left(2 \times 10^{-7} / 5 \times 10^{-4}\right)$ and $\left(5 \times 10^{-3} /\right.$ 5) $\mathrm{mg} \mathrm{L}^{-1}$ is equal to 1 within error limits $(1.0 \pm 0.1$ and $0.9 \pm 0.1$ respectively). Then with increasing of concentrations of caesium in solution the plateau is observed on the isotherm that can be an evidence of saturation of

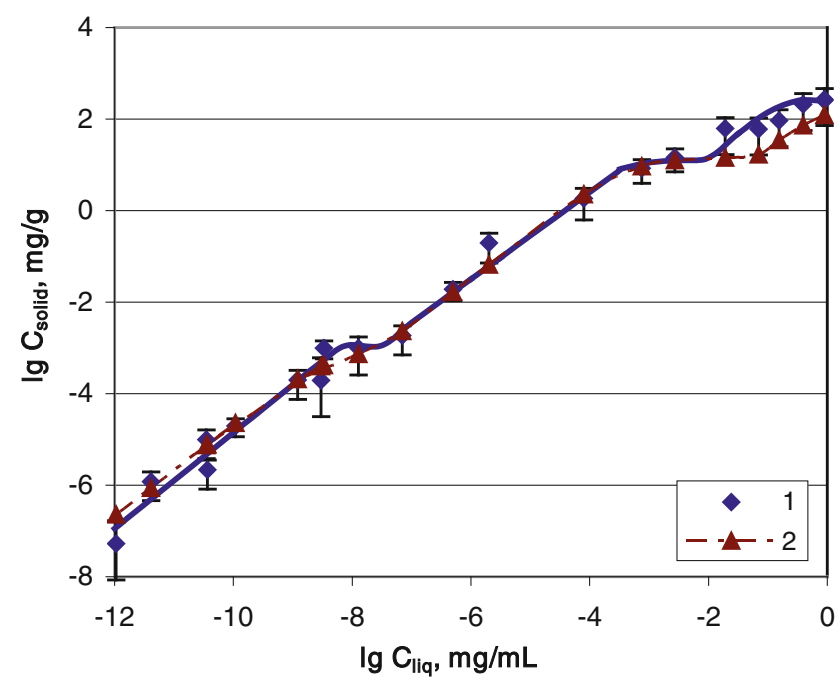

Fig. 1 Sorption isotherms of caesium by the mixed nickel-potassium ferrocyanide based on hydrated titanium dioxide from tap water at $\mathrm{pH}$ $7.8 \pm 0.2: 1$ experimental curve, 2 theoretical curve 
Table 1 The results of statistical data treatment of the sorption isotherm of caesium by the mixed nickel-potassium ferrocyanide based on hydrated titanium dioxide from tap water $(\mathrm{pH} 7.8 \pm 0.2)$

\begin{tabular}{|c|c|c|c|c|c|}
\hline \multirow{2}{*}{$\begin{array}{l}\text { Number of } \\
\text { linear part of } \\
\text { the isotherm }\end{array}$} & \multicolumn{2}{|c|}{$\begin{array}{l}\text { Parameters of equilibrium } \\
\lg C_{\mathrm{s}}=\lg K_{\mathrm{d}}+\operatorname{tg} a \times \lg C_{\text {liq }}\end{array}$} & \multirow{2}{*}{$\begin{array}{l}\text { Concentration limits } \\
\text { of linear parts (initial } \\
\text { concentrations in } \\
\text { solution) }\left(\mathrm{mg} \mathrm{L}^{-1}\right),\end{array}$} & \multirow{2}{*}{$\begin{array}{l}\text { Static exchange } \\
\text { capacity achieved } \\
\text { on the piece }\left(\mathrm{mg} \mathrm{g}^{-1}\right)\end{array}$} & \multirow{2}{*}{$\begin{array}{l}\text { Parameter of } \\
\text { sorption affinity } \\
\left(\mathrm{mL} \mathrm{mg}^{-1}\right)\end{array}$} \\
\hline & $\lg K_{\mathrm{d}} \pm \Delta \lg K_{\mathrm{d}}$ & $\operatorname{tg} a \pm \Delta \operatorname{tg} a$ & & & \\
\hline 1 & $5.6 \pm 1.0$ & $1.0 \pm 0.1$ & $2 \times 10^{-7} / 5 \times 10^{-4}$ & 0.001 & $2.14 \times 10^{8}$ \\
\hline 2 & $4.2 \pm 0.6$ & $0.9 \pm 0.1$ & $5 \times 10^{-3} / 5$ & 14.6 & 2,260 \\
\hline 3 & $2.4 \pm 0.1$ & $0.48 \pm 0.08$ & $50 / 500$ & 255 & 1.01 \\
\hline
\end{tabular}

respective sorption site. Filling of I and II types sorption sites can be satisfactorily approximated by Langmuir equation. The theoretically calculated sorption isotherm of caesium, based on suggestion about filling of all three types of sorption sites in accordance with Langmuir equation, is presented at Fig. 1 (curve 2). In case of sorption of caesium by III type sorption sites, Henry's law doesn't work and the slope of respective linear part is $(0.48 \pm 0.08)$. It's obvious that Langmuir isotherm cannot be used for interpretation of sorption of caesium at concentration range higher than $50 \mathrm{mg} \mathrm{L}^{-1}$. The sorption chemism of caesium at these concentrations differ from the same at lower concentrations. As it was mentioned in the work [24] for tin ferrocyanide, the Langmuir's model describes experimental data inaccurately at middle and large degrees of filling of sorption sites and sorption isotherms for caesium and other tested ions have an appearance of curves with bends.

Thus, filling of I and II types sorption sites can be described within the bounds of theory of ion exchange. Previously authors have shown [8] that I type sorption site corresponds to the phase of mixed nickel-potassium ferrocyanide. Used methods of research do not allowing ascertain the exact stoichiometry of forming compounds because of complexity of compound of forming ferrocyanide phase. The expected sorption chemism can be described by equilibrium (2):

$$
\begin{array}{ll}
\equiv \mathrm{TiO}-\mathrm{Ni}{ }_{\backslash}\left[\mathrm{Fe}(\mathrm{CN})_{6}\right] \mathrm{K}_{2}+2 \mathrm{Cs}^{+} \rightarrow & \equiv \mathrm{TiO}-\mathrm{Ni} i_{\backslash} \\
\equiv \mathrm{TiO}-\mathrm{Ni}^{>} & \left.\equiv \mathrm{FiO}-\mathrm{Ni}^{\prime}(\mathrm{CN})_{6}\right] \mathrm{Cs}_{2}+2 \mathrm{~K}^{+}
\end{array}
$$

Caesium easily replaces potassium (and probably part of nickel) ions locating in intercrystalline voids of matrix. Participation of nickel ions in the act of ion exchange can be explained by some non-equivalence of chemical bonds between $\mathrm{Ni}(\mathrm{II})$ in various locations and $\left[\mathrm{Fe}(\mathrm{CN})_{6}\right]^{4-}$ in the crystal lattice [5].

The II type sorption sites is titanium ferrocyanide. Presumably, it can be phases like $\mathrm{K}_{2}(\mathrm{TiO})\left[\mathrm{Fe}(\mathrm{CN})_{6}\right]$, $\mathrm{K}_{2}(\mathrm{TiO})_{3}\left[\mathrm{Fe}(\mathrm{CN})_{6}\right]_{2}$ and hardly probable $\mathrm{K}_{4} \mathrm{Ti}\left[\mathrm{Fe}(\mathrm{CN})_{6}\right]_{2}$, because its forming leads to degradation of the base (hydrated titanium dioxide) and decreasing of strength properties, meanwhile the sorbent possesses high mechanical strength. The expected sorption chemism of caesium is exchange of caesium ions for potassium or $\mathrm{H}_{3} \mathrm{O}^{+}$ions locating in intercrystalline voids.

$\mathrm{K}_{2}(\mathrm{TiO})\left[\mathrm{Fe}(\mathrm{CN})_{6}\right]+2 \mathrm{Cs}^{+} \rightarrow \mathrm{Cs}_{2}(\mathrm{TiO})\left[\mathrm{Fe}(\mathrm{CN})_{6}\right]+2 \mathrm{~K}^{+}$

In addition, physicochemical methods of research were used for identification of III type sorption sites and for description of mechanisms of sorption.

Electronic photographies of surface of initial sample of mixed nickel-potassium ferrocyanide based on hydrated titanium dioxide $(\mathrm{a}, \mathrm{c})$ and sample saturated by caesium (b, d) are presented at Fig. 2.

Electronic photographies allowing see a phase with various sized particles on the surface of spherical bead of initial sample of the mixed nickel-potassium ferrocyanide based on hydrated titanium dioxide (Fig. 2a). As a result of saturation of the sorbent by caesium disappearance of this phase (Fig. 2b) and appreciable transformation of texture of the sorbent surface (Fig. 2d) take place that is probably connected with chemical transformation of the surface and change of the phase.

Infrared spectra of samples of initial sorbent and sorbent after sorption of caesium are presented at Fig. 3. Two absorption peaks at 2,060 and 2,092 $\mathrm{cm}^{-1}$, corresponding to absorption frequencies of ferrocyanide ions, present at spectra of sorbents and corroborate the presence of ferrocyanides in the compound of sorbents. It is obvious, that reduction of intensity of the peak at $2,060 \mathrm{~cm}^{-1}$ relative to the peak at $2,092 \mathrm{~cm}^{-1}$ occurs as a result of sorption of caesium, that can be the evidence of expenditure of a compound, corresponding to this peak, during sorption. The absorption peak at $2,060 \mathrm{~cm}^{-1}$ probably corresponds to free ferrocyanide ion in compound of $\mathrm{K}_{4} \mathrm{Fe}(\mathrm{CN})_{6}$ or $\mathrm{Na}_{4}\left[\mathrm{Fe}(\mathrm{CN})_{6}\right]$ absorbed on the surface of the sorbent. Appearance of additional peaks at Raman spectrum indicates to possibility of presence of $\mathrm{Na}_{4}\left[\mathrm{Fe}(\mathrm{CN})_{6}\right]$. The presence of well soluble potassium and sodiun ferrocyanides in the sorbent is additionally corroborated by experiences on sorption of caesium. In spectrum of initial sorbent absorption peaks at 1,045 and $1,120 \mathrm{~cm}^{-1}$ present, 
Fig. 2 Texture of surface of mixed nickel-potassium ferrocyanide based on hydrated titanium dioxide: initial sample (a, c) and sample saturated by caesium $(\mathbf{b}, \mathbf{d})$
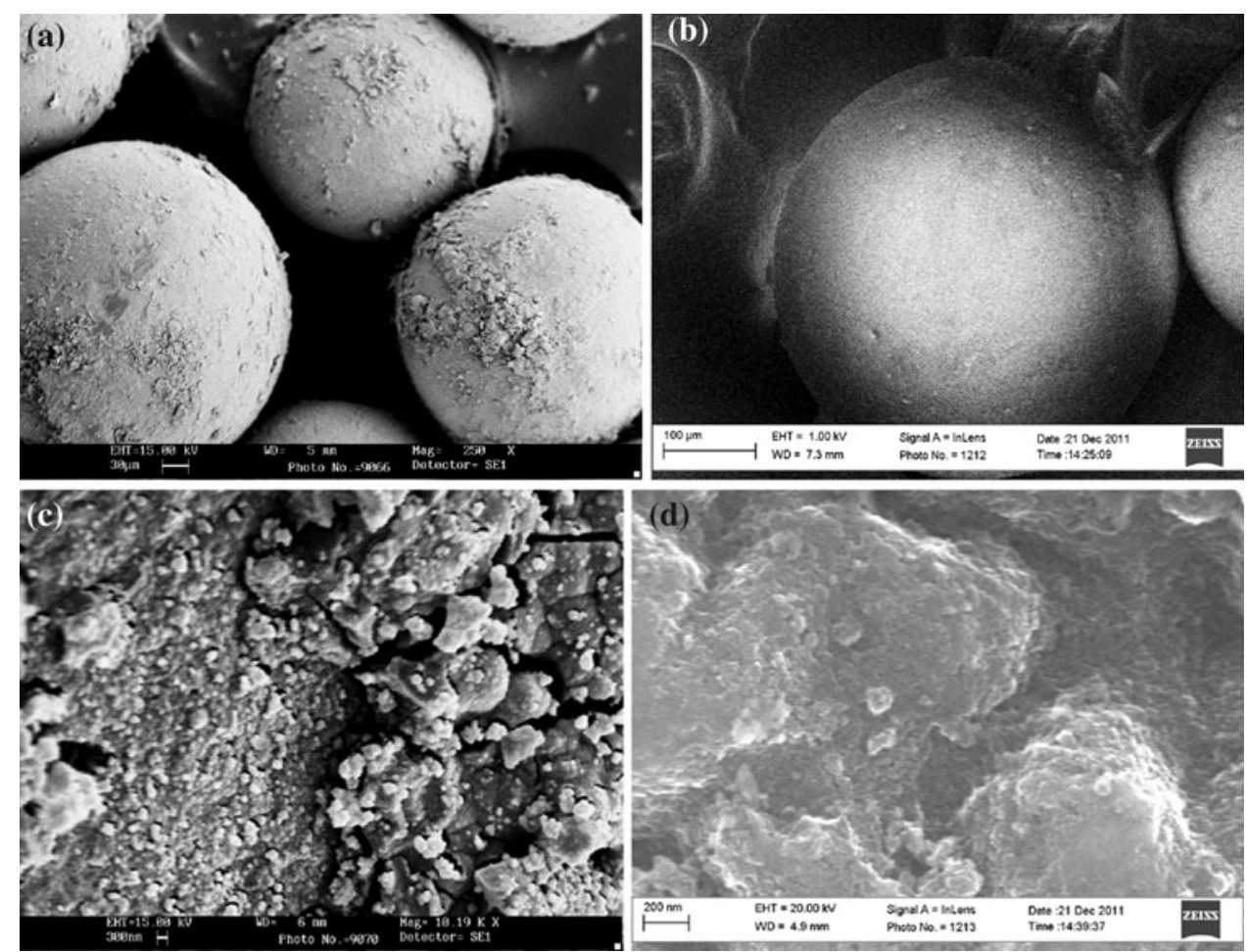

that unequivocally indicates to presence of the single covalent bonds $\mathrm{Ni}-\mathrm{O}$ (peaks at 1,118 and $1,040 \mathrm{~cm}^{-1}$ ) and absence of double bonds $\mathrm{Ni}=\mathrm{O}$. After saturation of the sorbent by caesium the additional unidentified absorption peak with minimum at $1,144 \mathrm{~cm}^{-1}$ appears in IR-spectrum. This is the evidence of suggestion that sorption of caesium arises from ion exchange processes as well as chemical reactions due to which caesium forms a compound with covalent bond.

Sorption of caesium at high initial concentrations of caesium in the solution $\left(>50 \mathrm{mg} \mathrm{L}^{-1}\right.$ ) probably can be realized at the expense of the following chemisms:

- Sorption of coordination compounds of caesium. Caesium possesses very low own complexing ability, but it can be incorporated into various coordination compounds as outer sphere cation, therefore this suggested chemism cannot be ruled out.

- Precipitation of mixed nickel-caesium ferrocyanide with aggregation of the precipitate in phase of the sorbent. For realization of such chemism concentrations enough for excess of solubility product are needed. In this case adsorbed (and probably crystallized with forming of its own phase) $\mathrm{K}_{4} \mathrm{Fe}(\mathrm{CN})_{6}$ presents on the surface and in pore space of the sorbent. Nickel can appear in near-surface layer of the sorbent and in the solution due to the following causes:

1) Presence of nickel unreacted on the last stage of synthesis of the mixed nickel-potassium ferrocyanide;
2) Nickel can be a product of ion exchange sorption on the mixed nickel-potassium ferrocyanide;

3) The mixed nickel-potassium ferrocyanide being a sparingly soluble compound, nevertheless possesses limited solubility; it can dissociate emitting nickel ions into the solution.

For example, the model of sorption kinetics of microcomponent by polyfunctional ion exchange resin in consideration of changing of forms of initial sorbate during sorption owing to its interaction with products of resin dissolving is analysed in the work [30]. The rate of redistribution among forms may affect kinetics of interphase distribution, therefore, study of sorption kinetics with no account taking of forms of a microcomponent in a solution is inconsistently.

It is shown in works [31-33] that in natural waters caesium is able to form various colloids and weak complex compounds with organic ligands. In absence of complexing agents caesium presents in water solutions mainly as simple monovalent ion [34]. Since Cs presents in natural waters only in trace amounts the forming of its own colloid forms is impossible. Forming of pseudoradiocolloids (radionuclide adsorbed and/or occupied by another nonradioactive colloid particles) is connected with processes of spontaneous migration of trace amounts of caesium from liquid phase to a surface of heterogeneous impurities always presenting in natural waters. Therefore, the pseudocolloid state of $\mathrm{Cs}$ is determined by processes of its 
Fig. 3 IR-spectra of samples of initial sorbent and sorbent after sorption of caesium: a general view of spectra, $\mathbf{b}$ view of spectra in the range of $1,900-2,200 \mathrm{~cm}^{-1}$, $\mathbf{c}$ view of spectra in the range of $900-1,300 \mathrm{~cm}^{-1}$

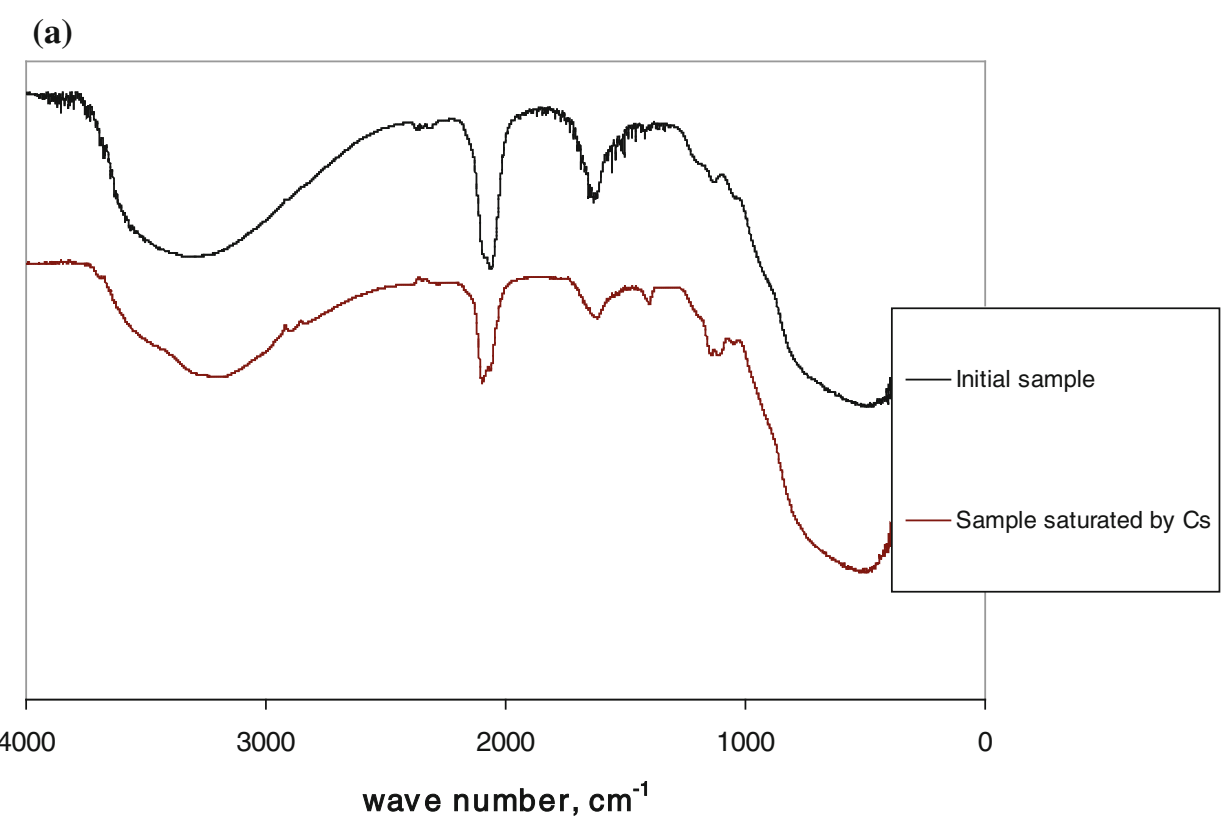

(b)

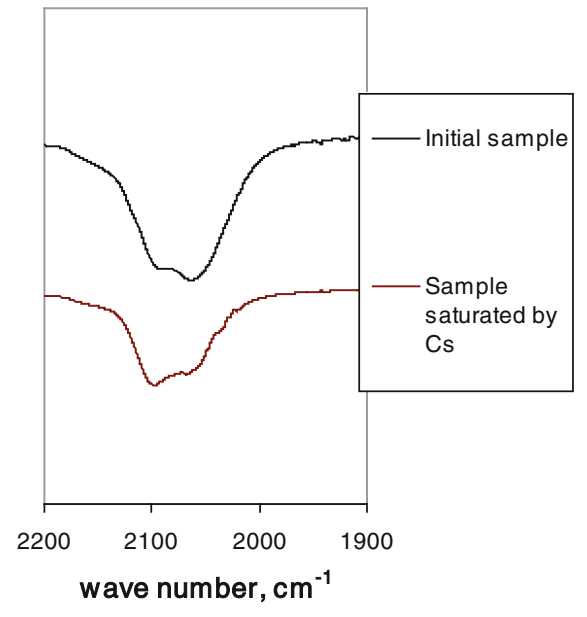

(c)

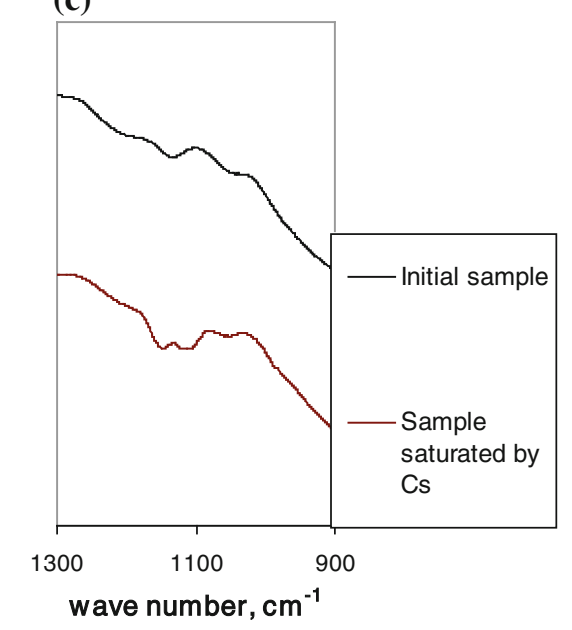

adsorption by colloids of silicic acid, iron and manganese hydroxides and some other compounds.

Our preliminary experiences have shown that contribution of colloid caesium forms in spiked tap water (in initial solutions) is not $>10 \%$ of overall amounts of caesium in the solution. Colloid particles containing caesium have size $>140 \mathrm{~nm}$. The most probable centres of their forming are transition metals hydroxides, organic and inorganic suspensions presenting in the water. Tests have also shown that under kinetic conditions amount of pseudocolloid caesium fraction is not changed during the kinetic test and begins to decrease 1 week later, that is connected with colloids destruction [35]. Thus, the presence of slight amounts of caesium pseudoradiocolloids did not affect sorption kinetics of caesium by mixed nickel-potassium ferrocyanide based on hydrated titanium dioxide.
A number of experiences on kinetics of caesium sorption at caesium concentrations $>50 \mathrm{mg} \mathrm{L}^{-1}$ were performed as a test of suggested hypotheses. Kinetics curves of sorption of caesium from tap water containing $100 \mathrm{mg} \mathrm{L}^{-1}$ of $\mathrm{Cs}$ by hydrated titanium dioxide saturated by nickel with additions potassium ferrocyanide (a) and by mixed nickel-potassium ferrocyanide based on hydrated titanium dioxide (b) are presented at Fig. 4.

It is obvious that all kinetic curves show a rapid first stage of sorption with duration up to $5 \mathrm{~min}$; then sorption rate dramatically decreases that is the evidence of almost complete realization of mechanism of sorption. The sorption rate at this stage significantly increases with increasing of concentration of ferrocyanide in solution (Fig. 4a).

To eliminate the possibility of sorption of caesium by hydrated titanium dioxide saturated by nickel, kinetic 

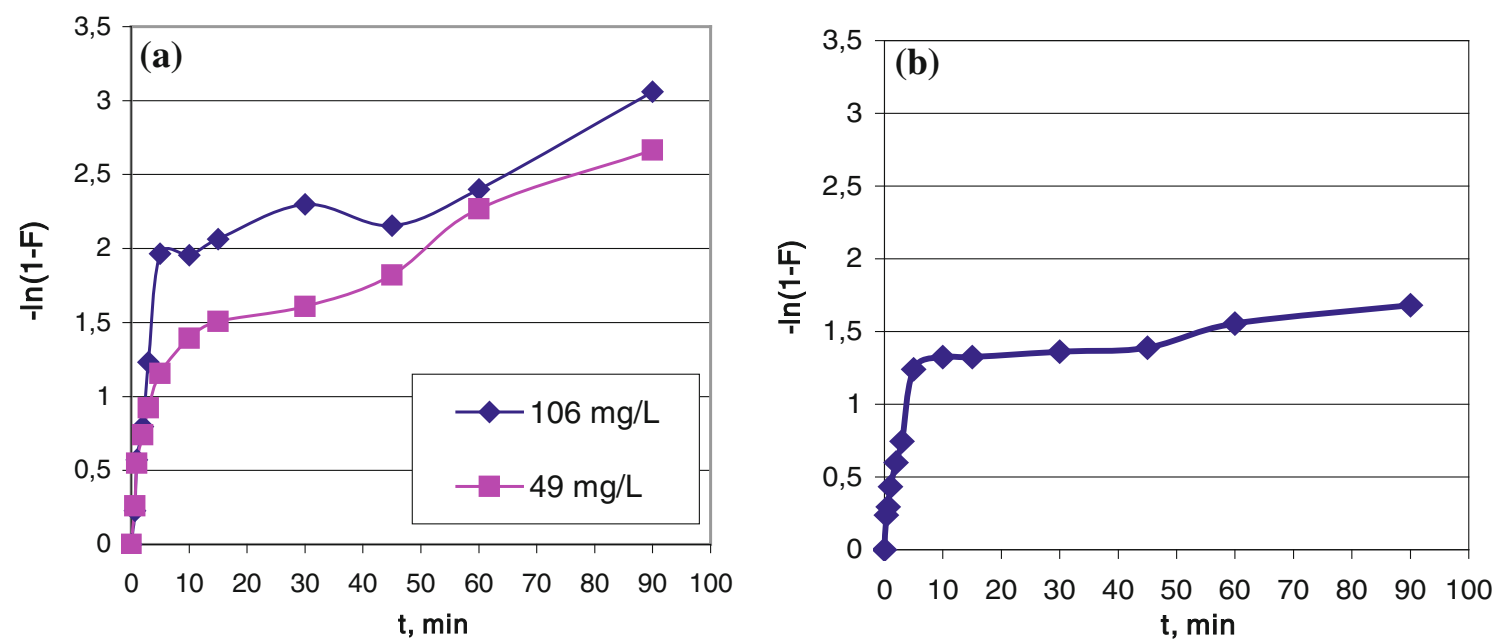

Fig. 4 Kinetics curves of sorption of caesium from tap water containing $100 \mathrm{mg} \bullet \mathrm{L}^{-1}$ of $\mathrm{Cs}$ : a by hydrated titanium dioxide saturated by nickel with additions potassium ferrocyanide, $\mathbf{b}$ by mixed nickel-potassium ferrocyanide based on hydrated titanium dioxide

experience was performed under the same conditions but without addition of $\mathrm{K}_{4} \mathrm{Fe}(\mathrm{CN})_{6}$ into the solution. The results have shown that caesium wes not sorbed under such conditions. Also kinetic experiences on sorption of caesium by hydrated titanium dioxide in presence and in absence of $\mathrm{K}_{4} \mathrm{Fe}(\mathrm{CN})_{6}$ in the solution were performed for detection of influence of complex formation on sorption of caesium. Obtained data have shown the absence of sorption of probable complex compounds of caesium with ferrocyanide ions. The results of sorption of caesium tap water containing $100 \mathrm{mg} \mathrm{L}^{-1}$ of Cs by various sorbents under kinetic conditions are presented at Table 2. Sorption degrees after $5 \mathrm{~min}\left(\mathrm{~S}_{1}\right)$ and at the end of the experience $\left(\mathrm{S}_{2}\right)$ are given for comparison.

The results of mathematical treatment of approximated linear parts of kinetic sorption curves are presented in Table 3.

Table 2 The results of sorption of caesium by various sorbents under kinetic conditions

\begin{tabular}{lrll}
\hline Sorbent & $\begin{array}{c}\text { Concentration } \\
\text { of } \mathrm{K}_{4} \mathrm{Fe}(\mathrm{CN})_{6}\end{array}$ & \multicolumn{2}{l}{ Sorption degree } \\
\cline { 3 - 4 }$\left(\mathrm{mg} \mathrm{L}^{-1}\right)$ & $\mathrm{S}_{1}$ & $\mathrm{~S}_{2}$ \\
\hline $\begin{array}{l}\text { Hydrated titanium dioxide } \\
\text { in } \mathrm{H}^{+}-\mathrm{Na}^{+} \text {form }\end{array}$ & 0 & 0 & 0 \\
Hydrated titanium dioxide & 106 & 0 & 0 \\
$\quad$ saturated by nickel & 49 & 0 & 0 \\
& 106 & 0.20 & 0.25 \\
Mixed nickel-potassium & 0 & 0.22 & 0.28 \\
ferrocyanide based on & & 0.29 & 0.33 \\
hydrated titanium dioxide & & & \\
\hline
\end{tabular}

Since at the same concentrations of stable caesium in the solution (Fig. 4a) sorption of Cs from solution with higher concentration of potassium ferrocyanide flows faster on the first stage, then some decreasing of sorption rate occurs on the second stage in this case. To all appearance, when concentration of caesium decreases down to a determinated value, the "rapid" mechanism of sorption becomes unavailable.

Kinetic experience in the range of high concentrations of caesium was performed for revelation of the role of precipitation in sorption caesium by mixed nickel-potassium ferrocyanide based on hydrated titanium dioxide. In case of realization of precipitation mechanism during sorption, the obtained kinetic curve must be look like curves presented at Fig. 4a, with presence of rapid first stage. Evidently, the general view of kinetic curve of sorption caesium by mixed nickel-potassium ferrocyanide based on hydrated titanium dioxide (Fig. 4b) is similar to those presented at Fig. 4a. The sorption flows rather intensively during the first $5 \mathrm{~min}$, then it dramatically decelerates and almost stops. Constants of rates of sorption of caesium by mixed nickel-potassium ferrocyanide based on hydrated titanium dioxide and by hydrated titanium dioxide saturated by nickel (in presence of $\left.49 \mathrm{mg} \mathrm{L}^{-1}\left[\mathrm{~K}_{4} \mathrm{Fe}(\mathrm{CN})_{6}\right]\right)$ are equal within error limits on the first stage of sorption. The slight differences of values of constants of sorption rates on the second stage of sorption is probably connected with difference of speed of transfer of ferrocyanide ions to near-surface layer of the sorbent. In case of the mixed nickel-potassium ferrocyanide based on hydrated titanium dioxide, ferrocyanide ions are located in pore space and near surface layer of the sorbent, that provides rapid and almost complete realization of mixed nickel-caesium ferrocyanide precipitation mechanism. In case of model experience, simulated release 
Table 3 Coefficients of equations of linear regressions for kinetic dependences of sorption of caesium on concentration of $\mathrm{K}_{4} \mathrm{Fe}(\mathrm{CN})_{6}$ in solution

\begin{tabular}{|c|c|c|c|c|c|}
\hline \multirow[t]{2}{*}{ Sorbent } & \multirow[t]{2}{*}{$\begin{array}{l}\text { Concentration } \\
\text { of } \mathrm{K}_{4} \mathrm{Fe}(\mathrm{CN})_{6}\left(\mathrm{mg} \mathrm{L}^{-1}\right)\end{array}$} & \multicolumn{2}{|l|}{$\begin{array}{l}\text { Linear part I } \\
y=a_{1} \times x+b_{1}\end{array}$} & \multicolumn{2}{|l|}{$\begin{array}{l}\text { Linear part II } \\
y=a_{2} \times x+b_{2}\end{array}$} \\
\hline & & $a_{1} \pm \Delta a_{1}$ & $b_{1} \pm \Delta b_{1}$ & $a_{2} \pm \Delta a_{2}$ & $b_{2} \pm \Delta b_{2}$ \\
\hline \multirow{2}{*}{$\begin{array}{l}\text { Hydrated titanium dioxide saturated } \\
\text { by nickel }\end{array}$} & 49 & $0.220 \pm 0.040$ & $0.176 \pm 0.102$ & $0.017 \pm 0.001$ & $1.159 \pm 0.053$ \\
\hline & 106 & $0.389 \pm 0.021$ & $0.042 \pm 0.055$ & $0.012 \pm 0.002$ & $1.845 \pm 0.084$ \\
\hline $\begin{array}{l}\text { Mixed nickel-potassium ferrocyanide } \\
\text { based on hydrated titanium dioxide }\end{array}$ & $\begin{array}{l}0 \text { (without addition } \\
\text { of } \mathrm{K}_{4} \mathrm{Fe}(\mathrm{CN})_{6} \text { ) }\end{array}$ & $0.224 \pm 0.016$ & $0.122 \pm 0.038$ & $0.005 \pm 0.001$ & $1.235 \pm 0.023$ \\
\hline
\end{tabular}

Table 4 Specific surface areas of samples of the mixed nickelpotassium ferrocyanide based on hydrated titanium dioxide

\begin{tabular}{ll}
\hline Sample & $S_{\mathrm{sp}} \pm \Delta S_{\mathrm{sp}}\left(\mathrm{m}^{2} \mathrm{~g}^{-1}\right)$ \\
\hline Initial sample & $123.0 \pm 2.5$ \\
Sample saturated by $\mathrm{Cs}$ & $158.3 \pm 1.5$ \\
\hline
\end{tabular}

of ferrocyanide ions into liquid phase as a result of interaction of the sorbent and solution, we added ferrocyanide ions to solution with their homogeneous distribution in the whole volume of solution, that can provide slower second stage of sorption.

The results, presented at Table 2, obviously demonstrate the realization of mechanism of precipitation of mixed nickel-caesium ferrocyanide. It is obvious that increasing of concentration of potassium ferrocyanide stimulates sorption of caesium; this can be used for increasing of final sorption degree.

Slightly higher equilibrium degree of sorption of caesium by mixed nickel-potassium ferrocyanide based on hydrated titanium dioxide in comparison with hydrated titanium dioxide saturated by nickel with addition of $\mathrm{K}_{4} \mathrm{Fe}(\mathrm{CN})_{6}$ can be easily explained by working of other two sorption sites, that give their contribution to overall static exchange capacity. However, at high concentrations of caesium, its sorption occurs mainly due to precipitation and the contribution ion exchange to sorption degree is insignificant.

The values of specific surface areas of samples of the mixed nickel-potassium ferrocyanide based on hydrated titanium dioxide are presented in Table 4.

Table 4 shows that specific surface area of the sorbent increases by $23 \%$ as a result of saturation by caesium. This increasing of specific surface area corroborates anew the possibility of forming of a new sorptive phase.

\section{Conclusions}

Sorption isotherm of caesium from tap water by mixed nickel-potassium ferrocyanide based on hydrated titanium dioxide is obtained for a wide range of concentrations of caesium. The general view of the isotherm shows that there are three types of specificity to caesium sorption sites in this sorbent. Each of these sorption sites works at defined concentration range and is characterized by unique values of distribution coefficients and static exchange capacity.

Occupation of sorption sites I and II is well approximated by Langmuir equilibrium, therefore sorption of caesium by mixed nickel-potassium ferrocyanide based on hydrated titanium dioxide in concentration range at $2 \times 10^{-7}-50 \mathrm{mg} \mathrm{L}^{-1}$ can be described within the bounds of theory of ion exchange.

The expected sorption chemism of caesium at high concentrations of caesium $\left(>50 \mathrm{mg} \mathrm{L}^{-1}\right)$ is precipitation of mixed nickel-caesium ferrocyanide in pore space of the sorbent. It allowing explain very high capacity of the sorbent to caesium ions and significant deviation from 1 of slope of the third linear part on the isotherm.

Acknowledgments This work was performed with financial support of Russian Federal task program "Scientific and pedagogical personnel of innovation Russia" for 2009-2013", (Grant no. 14.A18. 21.0313).

\section{References}

1. Volkhin VV, Kolesova SA, Kaloshnikova AF (1967) Rare alkaline elements. Science, Novosibirsk, pp 174-181

2. Ismail M, EI-Sourougy MR, Abdel MN, Aly HF (1998) Preparation, characterization, and utilization of potassium nickel hexacyanoferrate for the separation of cesium and cobalt from contaminated waste water. J Radioanal Nucl Chem 237(1-2): 97-102

3. Betenekov ND, Gubanova AN, Egorov YV et al (1976) Radiokhimiya 18(4):622-628

4. Bardov AI, Voroshilov YA, Zemlina NP et al (1999) Radiokhimiya 41(5):451-455

5. Kopyrin AA, Pyartman AK, Keskinov VA et al (1999) Radiokhimiya 41(3):236-238

6. Voronina AV, Semenishchev VS, Bykov AA, Kutergin AS, Nedobuh TA, Betenekov ND. The assessment of possibility of use of natural and modified aluminosilicates for rehabilitation of radioactive contaminated territories SCI conference: SCI conference: International conference on ion exchange (IEX 2012). 
Extended abstracts. Queens' college Cambridge. 2012. Soc Chem Ind 37-38

7. Milyutin VV, Gelis VM, Penzin RA (1993) Radiokhimiya 35(3):76-82

8. Voronina AV, Semenishchev VS, Nogovitsyna EV, Betenekov ND (2012) A study of ferrocyanide sorbents on hydrated titanium dioxide support using physicochemical methods. Radiochemistry 54(1):69-74

9. Kazemian H, Zakeri H, Rabbani MS (2006) $l$ Cs and Sr removal from solution using potassium nickel hexacyanoferrate impregnated zeolites. J Radioanal Nucl Chem 268(2):231-236

10. Rajec P, Orechovska J, Novak I (2000) NIFSIL: a new conposite sorbent for cesium. J Radioanal Nucl Chem 245(2):317-321

11. Orechovska J, Rajec P (1999) Sorption of cesium on composite sorbents based on nickel ferrrocyanide. J Radioanal Nucl Chem 242(2):387-390

12. Sharygin LM, Moiseev VE, Kuzmina RV et al (1986) Radiokhimiya 3:361-367

13. Sebesta F (1997) Composite sorbents of inorganic ion-exchangers and polyacrylonitrile binding matrix. J Radioanal Nucl Chem 220(1):77-88

14. Ismail M, EI-Sourougy MR, Abdel MN, Aly HF (1999) Equilibrium and kinetic studies of the sorption of cesium by potassium-nickel hexacyanoferrate complex. J Radioanal Nucl Chem 240(1):59-67

15. Seyfer GB (1980) Sorbents based on sparingly soluble ferrocyanides. In: Nickolsky BP (ed) Inorganic ion-exchange materials, vol 2. Leningrad State University, Leningrad, pp 9-17

16. Seyfer GB, Makarova ZA (1962) About zeolitic nature of transition metals ferrocyanides. J Inorg Chem 5:1208-1209

17. Renaud A, Cartraud P, Cointot A (1983) Zeolitic properties of mixed hexacyanoferrates(II): adsorption isotherms and differential heats of adsorption of water vapour. J Therm Anal 26:269-276

18. Egorov EV, Makarova SB (1971) Ion exchange in radiochemistry. Atomizdat, Moscow, p 408

19. Seyfer GB, Makarova ZA (1964) About zeolitic introduction of monovalent cations into precipitates of sparingly soluble ferrocyanides. J Inorg Chem 12:2782-2784

20. Volkhin VV, Zilberman MV et al (1975) Common characteristics of sorption features of bivalent transition metals. J Inorg Chem 1:54-59

21. Zilberman MV, Volkhin VV (1971) Structure of mixed copper ferrocyanide and respective products of molecular sorption. J Struct Chem 4:649-652

22. Volkhin VV, Kolesova SA et al (1971) About the nature of molecular sorption of alkaline metals salts by nickel ferrocyanide. J Inorg Chem 6:1611-1613
23. Zilberman MV, Kuznetsov VG, Volkhin VV (1974) About the structure of mixed nickel and sodium ferrocyanide. J Inorg Chem 7:1838-1841

24. Polyakov EV, Denisova TA, Maksimova LG, Zubkov VG, Bol'shakova GA, Surikov VT, Sokolova LL (1997) Molecular sorption on tin(II) ferrocyanides. Russ J Inorg Chem 42(3): 301-306

25. Betenekov ND, Semenistchev VS, Voronina AV (2008) The study of the chemical stability of matrixes for caesium immobilization based on thin-layer inorganic sorbents SCI conference: IEX 2008 recent advances in ion exchange theory and practice. London, Society of Chemical Industry 211-214

26. Semenishchev VS, Voronina AV, Bykov AA (2012) The study of sorption of caesium radionuclides by " $\mathrm{T}-55$ " ferrocyanide sorbent from various types of liquid radioactive wastes. Radioanal Nucl Chem. doi:10.1007/s10967-012-2299-4

27. Spectral Database for Organic Compounds. http://riodb01.ibase. aist.go.jp/sdbs/cgi-bin/direct_frame_top.cgi

28. Voronina AV, Semenistchev VS, Betenekov ND, Berezin MA, Yakhina ES (2009) The sorbent for combined extraction of caesium and strontium from high-salted liquid radioactive wastes VIII Finnish-Russian Symposium on Radiochemistry 4-5, University of Turcu and Abo Academi University, Finland, pp 41-42

29. Voronina AV, Semenishchev VS (2013) Effect of surface modification of hydrated titanium dioxide on its selectivity to strontium. Radiochemistry 55(1):94-97

30. Polyakov EV, Betenekov ND (1988) Linear sorption mechanism for a microcomponent sorbate by independent pathways. Kinet Catal 29(3.2):560-566

31. Rudenko LI, Dzhuzha OV, Khan VE (2007) Semipermeable dynamic membranes for ultrafiltration treatment of ground waters to remove radionuclides. Radiochemistry 49(2):201-203

32. Odintsov AA, Khan VE, Krasnov VA, Pazukhin EM (2007) Radionuclides in ground waters from observation holes in the shelter local area. Radiochemistry 49(5):534-540

33. Sabodina MN (2008) Relationships of radionuclides behaviour during creation of anthropogeneous geochemical barrier based on aluminosilicates. Abstract of candidate's thesis. Moscow state university, Moscow. http://www.phyche.ac.ru/files/Sabodina.pdf

34. Nesmeyanov AN (1972) Radiochemistry. Chemistry, Moscow, p 592

35. Voronina AV, Gortsunova XR, Semenishchev VS (2011) The influence of forms of caesium in drinking water on sorption statics and kinetics by T-55 sorbent. In: Prokhorov NB et al (eds) Materials of XI International science symposium and exposition pure water of Russia. RosNIIVH, Ekaterinburg, pp 205-208 